\title{
Vibration Detection in Water Pipelines Leakage Using Wireless Three-Axis Accelerometer Sensor
}

\author{
${ }^{1}$ Mohd Ismifaizul Mohd Ismail, ${ }^{1}$ Rudzidatul Akmam Dziyauddin, \\ ${ }^{2}$ Noor Azurati Ahmad and ${ }^{1}$ Norulhusna Ahmad \\ ${ }^{1}$ UTM Razak School of Engineering and Advanced Technology, \\ Universiti Teknologi Malaysia, Kuala Lumpur, Malaysia \\ ${ }^{2}$ School of Advance Informatics System \\ Universiti Teknologi Malaysia, Kuala Lumpur, Malaysia \\ ${ }^{1}$ ismifaizul@gmail.com, ${ }^{1}$ rudzidatul.kl@utm.my, ${ }^{1}$ norulhusna.kl@utm.my, \\ 2azurati@utm.my
}

\begin{abstract}
Leaking pipes are a primary concern for water utilities around the globe as they compose a major portion of revenue loss. An acoustic method is preferred by the water industry to detect and localise leaks in water pipelines. However, the acoustic leak detection method is only feasible for metal pipes and has several limitations when applied to soft materials, like plastic pipes. Therefore, this study aims to investigate a vibration technique to detect leakage on plastic water pipeline using wireless accelerometer sensor, namely 6DOF accelerometer sensor called MPU6050 across $x$-, $y$-and z-axis. A 25-mm diameter of Acrylonitrile Butadiene Styrene $(A B S)$ pipe with a length of approximately 10 meters was developed as a water pipeline testbed. The MPU6050 measured the vibration on the water pipeline across $x$-, $y$ - and z-axis, over ZigBee networks. The vibration signals were then compared between the three sensors and analysed by extracting the signal features in time and frequency domains. The sensors were examined based on three different cases, which are no pipe leakage, a 1-mm leak, and a 3-mm leak. The accelerometer sensor demonstrated a significant difference between no leak and leak conditions when the water pressure is in the range of 0.6 to $1.2 \mathrm{kgf} / \mathrm{cm}^{2}$ for time domain. For different leak size cases, MPU6050 can identify leak size cases just not from the $x$ - , but also from z-axis data. Based on new experimental findings, this paper also proposes an MPU6050 procedure in detecting the conditions of the plastic water pipeline including the sizes of the leaks.
\end{abstract}

Keywords: Wireless sensor node; MPU6050; Time domain analysis; Water pipeline leakage; procedure analysis; $x$-axis; $y$-axis; $z$-axis

\section{Introduction}

Since last decade, the population growth and the cost of access to water resources are increased with the changes of the climatic conditions. Water industries in many countries have identified the problem of limited water resources, and counter measures are taken to foster better water management system [2]. Water treatment processes that produce clean water for human consumption are expensive, and it is in the government's interest to maintain a pipeline system that prevents the generation of non-revenue water (NRW). NRW is observed when the amount of water produced by the water treatment centre is higher than the amount of water recorded in metered bills [3], [4]. A low NRW indicates that a pipeline system is highly efficient whereby the government takes immediate action to repair the pipeline system.

Received (August 14, 2017), Review Result (November 20, 2017), Accepted (November 24, 2017) 
The problem statement of this study is divided into three main parts: leakage detection methods, single axis analysis, and localisation of the leak point. Most researchers used the vibration data [5]-[8] to determine the location of the leak point on the water pipeline system. Two vibration sensors are positioned on the water pipeline and a cross correlation method is used to identify the location of the leaks. Nevertheless, previous studies [5]-[8] have not applied the vibration technique to detect the conditions of the water pipeline and the sizes of the leaks. They only used the internal water pressure data to determine the conditions of the water pipeline whether leakage or no leakage. Until recently, there have been no reliable evidence that the vibration sensor can be used to identify the conditions of the water pipeline and the sizes of the leaks.

The aim of this paper is to propose a procedure for plastic water pipeline leakage detection including the sizes of leaks using three-axis accelerometer sensors. The key objectives of this paper are stated as (i) to evaluate and analyse the performance of threeaxis MPU6050 accelerometer sensors and the vibration signals generated from the abovementioned sensors by extracting the features from time and frequency domain, and (ii) to propose a procedure in identifying the conditions of the plastic water pipeline including the size of leaks for each sensor based on experiments.

The previous study and system development is explained in Section 2 and 3. The water pipeline experiment setting is described in Section 4. The results and analysis are explained in Section 5. The propose procedure analysis is discussed in Section 6. Section 7 concludes this paper.

\section{State-of-the-art}

Current methods are divided into three large groups: software-based methods, biological methods and hardware-based methods, as depicted in Figure 1. Software-based methods use various types of computer software to analyse and detect leaks in pipeline systems. This method is used to measure internal pipeline parameters, including pressure, flow rate and temperature. Conventional methods require experienced personnel who walk along a pipeline and look for unusual patterns near the pipeline based on odours or sounds due to a leak. Hardware-based methods detect leaks by visual observation or using appropriate measurement equipment. In addition to these three groups of transient-based analysis methods, many leak detection techniques are available. However, none of these techniques are completely successful or reliable in all leak detection cases because they can be imprecise and time-consuming or suitable only for limited pipeline segments [9]. Ideally, pipeline operators and owners of the water company aim to employ simple, robust and highly accurate methods for detecting and locating leaks in the water pipeline system [10].

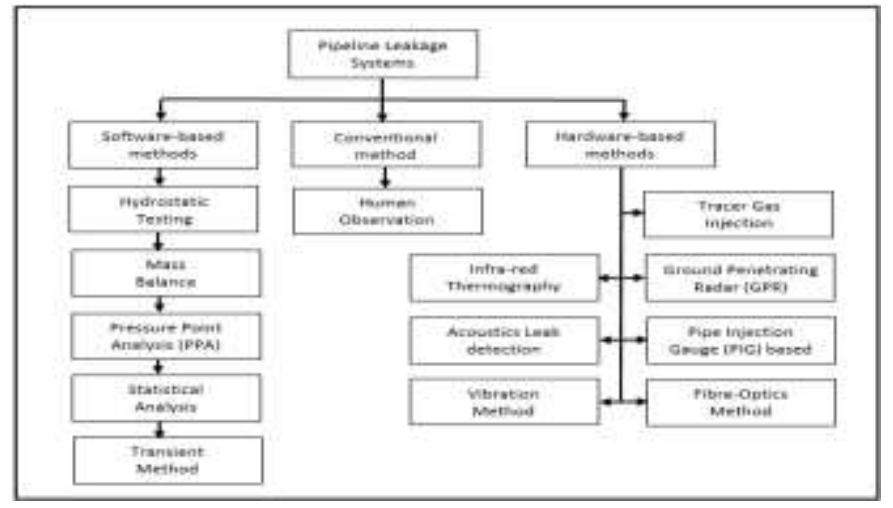

Figure 1. Groups of Water Pipeline System Methods

Table 1 shows the key attributes of leak detection hardware-based methods, including 
leak sensitivity, estimated location, false alarms, maintenance requirements and cost. The leak sensitivity is the smallest size of leak in the water pipeline system that can be detected, and a false alarm occurs when a water pipeline leak is incorrectly detected.

Table 1. Key Attribute of Leak Detection Methods

\begin{tabular}{|c|c|c|c|c|c|c|c|}
\hline Method & $\begin{array}{c}\text { Leak } \\
\text { Sensitivit } \\
\mathbf{y}\end{array}$ & $\begin{array}{l}\text { Location } \\
\text { Estimate }\end{array}$ & $\begin{array}{c}\text { Operatio } \\
\text { nal } \\
\text { Change }\end{array}$ & $\underset{\text { ty }}{\text { Availabili }}$ & $\begin{array}{c}\text { False } \\
\text { Alarm }\end{array}$ & $\begin{array}{l}\text { Maintena } \\
\text { nce } \\
\text { Require } \\
\text { ment }\end{array}$ & Cost \\
\hline $\begin{array}{c}\text { Convention } \\
\text { al Method } \\
{[11]}\end{array}$ & $\mathrm{HIGH}$ & NO & NO & YES & $\begin{array}{c}\text { MEDIU } \\
\text { M }\end{array}$ & MEDIUM & HIGH \\
\hline \multicolumn{8}{|c|}{ Software-Based Methods } \\
\hline $\begin{array}{c}\text { Hydrostatic } \\
\text { s [12] }\end{array}$ & $\mathrm{HIGH}$ & NO & NO & YES & HIGH & $\mathrm{HIGH}$ & HIGH \\
\hline $\begin{array}{c}\text { Mass } \\
\text { Balance } \\
{[13]-[15]}\end{array}$ & LOW & NO & NO & YES & HIGH & LOW & LOW \\
\hline $\begin{array}{l}\text { Pressure } \\
\text { Point } \\
\text { Analysis } \\
\text { (PPA) [16] }\end{array}$ & $\mathrm{HIGH}$ & NO & NO & YES & HIGH & $\mathrm{HIGH}$ & HIGH \\
\hline $\begin{array}{c}\text { Statistical } \\
\text { analysis } \\
\text { model } \\
\text { method [17], } \\
{[18]} \\
\end{array}$ & $\mathrm{HIGH}$ & NO & NO & YES & $\begin{array}{c}\text { MEDIU } \\
\mathrm{M}\end{array}$ & MEDIUM & HIGH \\
\hline $\begin{array}{c}\text { Transient } \\
\text { Based } \\
\text { method [12], } \\
{[18]-[31]}\end{array}$ & $\mathrm{HIGH}$ & NO & NO & YES & $\begin{array}{c}\text { MEDIU } \\
\mathrm{M}\end{array}$ & MEDIUM & $\mathrm{HIGH}$ \\
\hline \multicolumn{8}{|c|}{ Hardware-Based Methods } \\
\hline $\begin{array}{c}\text { Visual } \\
\text { Observation } \\
{[11],[17]}\end{array}$ & $\mathrm{HIGH}$ & YES & NO & YES & $\begin{array}{c}\text { MEDIU } \\
\mathrm{M}\end{array}$ & LOW & $\begin{array}{c}\text { MEDIU } \\
\mathrm{M}\end{array}$ \\
\hline $\begin{array}{c}\text { Tracer gas } \\
\text { injection } \\
{[19],[32]}\end{array}$ & $\mathrm{HIGH}$ & YES & NO & YES & LOW & $\mathrm{HIGH}$ & $\mathrm{HIGH}$ \\
\hline $\begin{array}{c}\text { Infra-red } \\
\text { thermograp } \\
\text { hy [32] }\end{array}$ & HIGH & YES & NO & YES & $\begin{array}{c}\text { MEDIU } \\
\text { M }\end{array}$ & $\mathrm{HIGH}$ & HIGH \\
\hline $\begin{array}{c}\text { Ground- } \\
\text { Penetrating } \\
\text { Radar } \\
\text { (GPR) [16], } \\
\text { [20], [21], } \\
\text { [23], [24], } \\
\text { [33] }\end{array}$ & $\mathrm{HIGH}$ & NO & NO & YES & HIGH & MEDIUM & HIGH \\
\hline $\begin{array}{c}\text { Acoustics } \\
{[5],[34]-} \\
{[36]}\end{array}$ & $\mathrm{HIGH}$ & YES & NO & YES & HIGH & MEDIUM & HIGH \\
\hline Pipeline & HIGH & YES & $\mathrm{NO}$ & YES & MEDIU & MEDIUM & HIGH \\
\hline
\end{tabular}




\begin{tabular}{|c|c|c|c|c|c|c|c|}
\hline $\begin{array}{c}\text { Inspection } \\
\text { Gauge } \\
\text { (PIG) }\end{array}$ & & & & & $\mathrm{M}$ & & \\
\hline $\begin{array}{c}\text { Vibration } \\
{[5],[7],} \\
{[37]-[53]}\end{array}$ & HIGH & YES & NO & YES & $\begin{array}{c}\text { MEDIU } \\
\text { M }\end{array}$ & LOW & LOW \\
\hline
\end{tabular}

The acoustics leak detection method can be systematically used in water pipeline systems and detects noise that is generated from leaks in the pipeline system. The acoustic technique has been widely used in the water industry and produces effective results for detecting and localizing leaks in pipeline systems [54]. Although the acoustic leak detection method has several limitations, it works well for detecting and locating leaks in metal pipes. However, this method does not perform well when applied to pipes made of soft materials, such as plastic [29], because soft pipes are more elastic and reduce sound waves by $300-600 \mathrm{~m} / \mathrm{sec}$. Due to their viscoelastic properties, plastic pipes also absorb sound energy (weakening the sound waves). However, the high-frequency noise increases when the sound waves travel along the water pipeline system. Analysing these noise signals will make this process more complicated [23]. The accuracy of leakage detection is also affected by the presence of air in the pipeline system. To improve the limitations of the acoustic method for a plastic pipeline system, the vibration method is used to detect and locate leaks. When the acoustic and vibration methods are compared for a real plastic water pipeline, the vibration sensor is the most accurate sensor for detecting and locating leaks. In fact, cross-correlation analysis is used to analyse acoustic and vibration data to detect and locate leaks [6].

\section{System Development}

A water pipeline test bed system has been designed and developed in a soil laboratory at the civil facility at Universiti Teknologi Malaysia (UTM). The test bed was designed using an inch diameter of ABS pipe with a length of approximately 10 meters. This test bed is an enhancement of the design from the PVC pipe experiment because it uses ABS pipe to measure leak vibration noise [37]-[39]. The test bed water pipeline has a water pump to provide water flow and pressure in the pipeline, and the end of the pipeline is connected to two ball valves. The water is circulated in the test bed system on command using a water pump capable of providing pressures of 0.6 to $1.6 \mathrm{kgf} / \mathrm{cm}^{2}$ and water flow velocities of 10 to 25 liter/sec. The function of the valve is to control the pressure and water flow in the pipeline system. An acceleration sensor (MMA7361, MPU6050 and ADXL335) is attached to the ABS water pipeline system to collect vibration data. The vibration data are analyzed using the signal analysis method to detect leaks and determine the sizes of the leaks.

Figure 2 illustrates the system architecture of the water pipeline monitoring system used in this work. The prototype of the pipeline system includes the water pump, flow rate meter, pressure meter, leak pipes and two manual valves. The function of a water pump is to generate the water flow and the water pressure in the pipeline system. The water system is designed to recycle the water intake during the experiments conducted. 


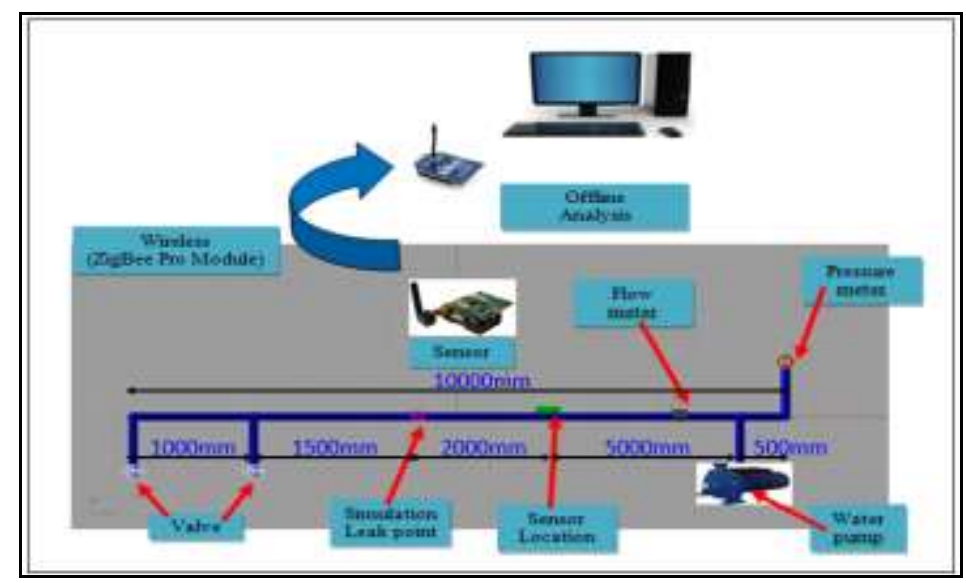

Figure 2. Real Simulation Pipe system for Testing Method [38], [39]

A block diagram of the wireless sensor system used in this study is illustrated in Figure 3. Three main components, namely, accelerometer sensors, Arduino UNO controller board, ZigBee module are employed in the water pipeline testbed. The sensor nodes are developed with accelerometer sensor and Arduino UNO controller board. The wireless sensor node is connected to ZigBee wireless transceiver for sending vibration data through wireless to a storage and processing unit.

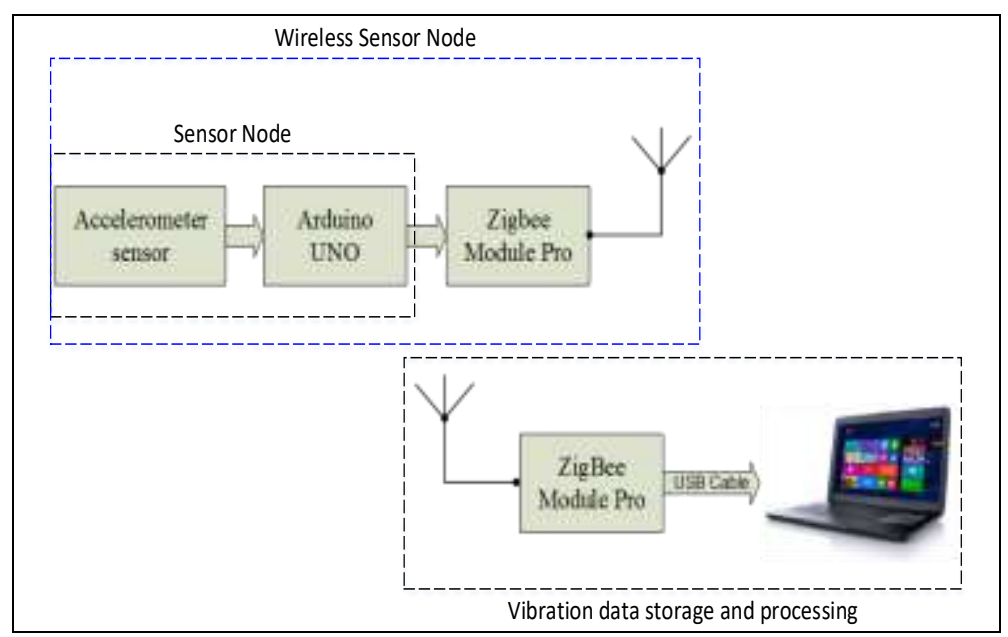

Figure 3. A Block Diagram of the Wireless Sensor System [38], [39]

\subsection{Hardware Design}

The type of sensor installed on the pipeline system is 6DOF SENSOR (MPU6050) with a water pressure and a liquid flow rate meter. Figures 4(a) to 4(b) show the wiring and block diagram of the MPU6050 sensor to the Arduino controller board, respectively. The Arduino board is used as a control board to read the data from the sensors and they collect the vibration data in three different dimensions, the $\mathrm{x}-, \mathrm{y}-$ and $\mathrm{z}$-axis. 


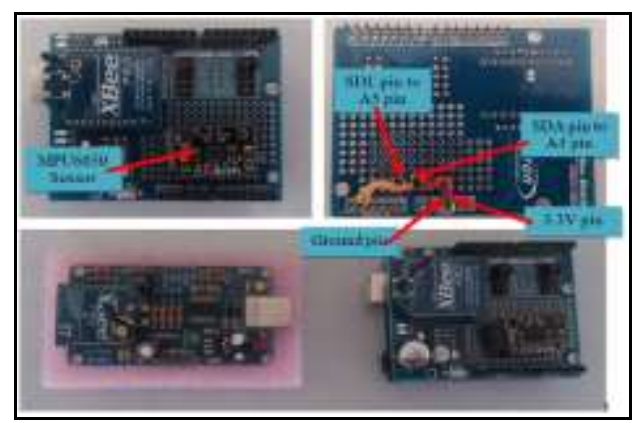

(a)

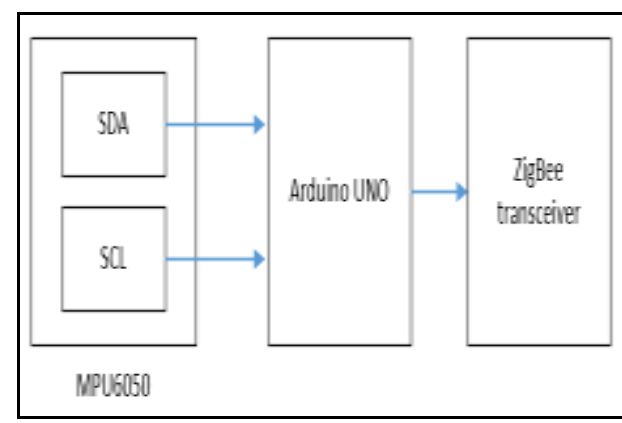

(b)

\section{Figure 4. The Wiring and Block Diagram of the MPU6050 Sensor to the Arduino ZigBee Prototype Shield}

The 6DOF sensor - MPU6050 sensor comprises the accelerometer and the gyrometer to collect the vibration data. The 6DOF sensor or six-axis sensor includes the three-axis of accelerometer and three-axis of gyrometer. The MPU6050 sensor using first-in first-out (FIFO) technique to send the data from sensor to processor. The processor using a twowire interface comprises of signal serial data (SDA) and serial clock (SCL), which is based on inter-integrated circuit $\left(\mathrm{I}^{2} \mathrm{C}\right)$ interface. On the other hand, the accelerometer and the gyrometer units are gravity, $g\left(1 g=9.81 \mathrm{~ms}^{-2}\right)$ and degrees per second $(\% / \mathrm{s})$, respectively. Figure 3 illustrates the position of MPU6050 on the water pipeline system in which the $\mathrm{x}$-axis is same direction with the water flow in the pipeline [55], [56].

\subsection{Software Design}

The process flow of acceleration data reading from MPU6050 is shown in Figure 5. The vibration data is read by MPU6050 sensor, and the data is sent via serial to data collection and processing system. The Arduino UNO controller used $\mathrm{I}^{2} \mathrm{C}$ coding technique to read the data from the accelerometer sensor. Initially, the Arduino UNO set $\mathrm{I}^{2} \mathrm{C}$ function for reading data from MPU6050 sensor using FIFO technique. The Arduino requests data from the sensor, and the sensor will then response. The second step is the accelerometer sensor offset is declared for the three-axis of the MPU6050 sensor, which are $\mathrm{x}-, \mathrm{y}-$ and $\mathrm{z}$-axis. The accelerometer sensor offset is used for the final results after converting acceleration data to $g$ unit $\left(1 g=9.81 \mathrm{~ms}^{-2}\right)$. For the third and fourth steps, the accelerometer sensor is initialised using $\mathrm{I}^{2} \mathrm{C}$ to check the connection between Arduino UNO controller board and MPU6050. Next, the Arduino UNO controller board requested the acceleration data from the MPU6050 sensor. 


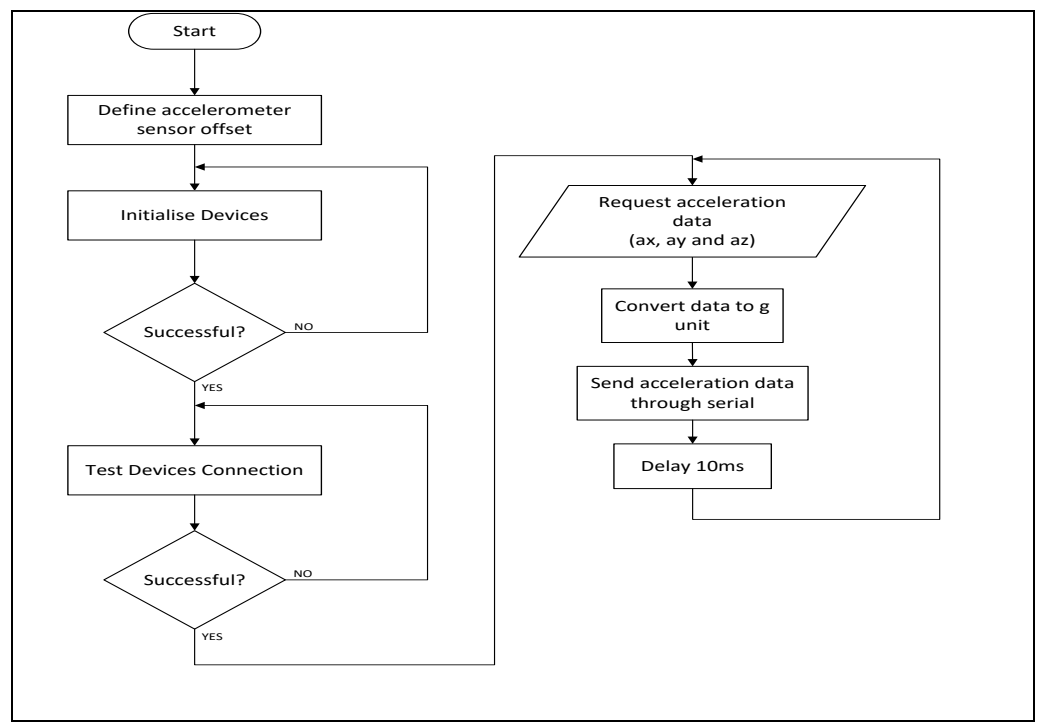

Figure 5. Software Flow for 6DOF SENSOR - MPU6050

\section{Experimental Setup}

The objective of the experiment is to quantify the performance of the MPU in detecting the conditions of the water pipeline and differentiate the sizes of the leaks for varying water pressure by using time domain analysis. The experiment configuration used in this experiment is listed in Table 2. The distance between the leaking point and the sensors is constant at $1.5 \mathrm{~m}$ (maximum distance) across all the sensors. However, the water pressure in the pipe is varied from 0.6 to $1.2 \mathrm{kgf} / \mathrm{cm}^{2}$. The vibration data is collected from three different axes: $\mathrm{x}-, \mathrm{y}-$ and $\mathrm{z}$-axis at an interval of $10 \mathrm{~ms}$ and is transmitted to a data storage over a wireless network called ZigBee. The data is collected for three times over 2 minutes.

Table 2. Experiment Parameters

\begin{tabular}{|c|c|}
\hline Parameter & Values \\
\hline Type of Pipe & ABS \\
\hline Pipe length $(\mathrm{m})$ & 10.0 \\
\hline Type of vibration Sensor & MPU6050 \\
\hline $\begin{array}{l}\text { Distance between pipe } \\
\text { leaking and sensor }(\mathrm{m})\end{array}$ & 1.5 \\
\hline $\begin{array}{l}\text { Duration of data collection } \\
\text { (s) }\end{array}$ & 120 \\
\hline Time sampling (ms) & 10 \\
\hline Water pressure $\left(\mathrm{kgf} / \mathrm{cm}^{2}\right)$ & $\begin{array}{l}0.6 \\
0.8 \\
1.0 \\
1.2\end{array}$ \\
\hline Size of leak holes & $\begin{array}{cc}\text { i. } & \text { No Leak } \\
\text { ii. } & 1-\mathrm{mm} \\
\text { iii. } & 3-\mathrm{mm}\end{array}$ \\
\hline
\end{tabular}




\section{Results and Analysis}

Figures 6 show the results of the average vibration $(g)$ by varying water pressure from 0.6 to $1.2 \mathrm{kgf} / \mathrm{cm}^{2}$ for different axes. The average data decreases for $1-\mathrm{mm}$ leak from 0.8 $\mathrm{kgf} / \mathrm{cm}^{2}$ to $1.2 \mathrm{kgf} / \mathrm{cm}^{2}$, as shown in Figure 5(a), which decreases from $0.0631 \mathrm{~g}$ to $0.0229 \mathrm{~g}$. However, the no leak vibration data decreases from $0.6 \mathrm{kgf} / \mathrm{cm}^{2}$ to $0.8 \mathrm{kgf} / \mathrm{cm}^{2}$ and 3-mm leak decreases from $0.8 \mathrm{kgf} / \mathrm{cm}^{2}$ to $1.0 \mathrm{kgf} / \mathrm{cm}^{2}$. Figure $5(\mathrm{~b})$ shows the average vibration data for MPU6050 across $\mathrm{x}$-axis in an upward trend between $0.8 \mathrm{kgf} / \mathrm{cm}^{2}$ and $1.2 \mathrm{kgf} / \mathrm{cm}^{2}$ for no leak and 3-mm leak. However, the vibration data shows a fluctuation from $0.8 \mathrm{kgf} / \mathrm{cm}^{2}$ to $1.2 \mathrm{kgf} / \mathrm{cm}^{2}$ for $1-\mathrm{mm}$ leak. The average vibration data for MPU6050 across $\mathrm{x}$-axis demonstrates a downward trend between $0.8 \mathrm{kgf} / \mathrm{cm}^{2}$ and $1.2 \mathrm{kgf} / \mathrm{cm}^{2}$ for no leak and 3-mm leak, as illustrated in Figure 5(c). However, the vibration data show a fluctuation from $0.8 \mathrm{kgf} / \mathrm{cm}^{2}$ to $1.2 \mathrm{kgf} / \mathrm{cm}^{2}$ for $1-\mathrm{mm}$ leak. In general, the MPU6050 follows the Bernoulli principle for all conditions and the sizes of the leak.
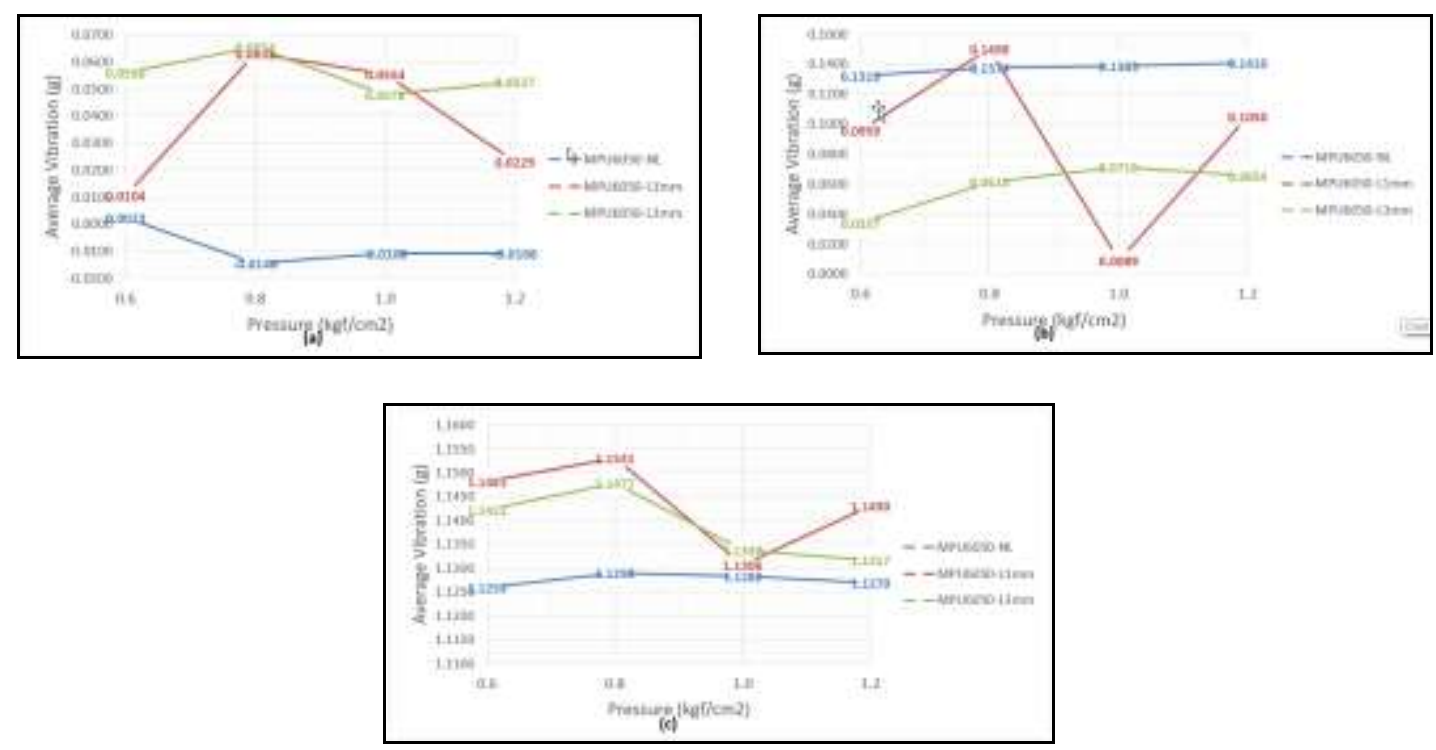

\section{Figure 6. Average Vibration (g) versus Distance $(m)$ for (a) x-axis, (b) y-axis and (c) z-axis}

Table 3 summarises the key findings of the MPU6050 across all pressure for different axes at $1.5 \mathrm{~m}$. Based on the Bernoulli principle, the cases of no leak, 1-mm and 3-mm leaks are represented as NL, L1 and L3, respectively are compared in the table. The grey and white boxes indicate the true and false results. Ideally, the vibration of the leak must be higher than that of no leak [57], [58].

Based on Table 3, the MPU6050 sensor is able to identify the conditions of the water pipeline across $\mathrm{x}$ - and z-axis; not for $\mathrm{y}$-axis. In addition to that, the data from $\mathrm{x}$-axis can identify the sizes of the leaks when the water pressure is varied between $0.6 \mathrm{kgf} / \mathrm{cm}^{2}$ and $1.2 \mathrm{kgf} / \mathrm{cm}^{2}$ apart from $1.0 \mathrm{kgf} / \mathrm{cm}^{2}$ that can be determined using the data from z-axis. Thus, these findings suggest that the abnormal and normal conditions (no leak) comprising the sizes of the leaks can be detected just not from X-axis, as considered from previous studies [59], but also from z-axis. However, this is not the case for $y$-axis of MPU6050. 
Table 3. Summary of the Water Pipeline Conditions for VARYING PressurE $\left(0.6\right.$ to $\left.1.2 \mathrm{kgf} / \mathrm{cm}^{2}\right)$

\begin{tabular}{|c|c|c|c|c|c|c|c|c|c|c|c|c|}
\hline \multirow{2}{*}{ Sensors } & \multicolumn{4}{|c|}{ X-Axis } & \multicolumn{4}{|c|}{ Y-Axis } & \multicolumn{4}{|c|}{ Z-Axis } \\
\hline & 0.6 & 0.8 & 1.0 & 1.2 & 0.6 & 0.8 & 1.0 & 1.2 & 0.6 & 0.8 & 1.0 & 1.2 \\
\hline \multirow{3}{*}{ MPU6050 } & $11 \times N$ & $11 \times N 1$ & I1SNL & $11>N 1$ & $11<N \mathrm{~L}$ & $L 1>N L$ & 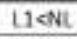 & $11<\mathrm{NL}$ & $11>\mathrm{NL}$ & $11 \times N 1$ & $11 \times N 1$ & $1.1>\mathrm{NI}$ \\
\hline & LaNAL & USPAL & $\mathrm{L}>\mathrm{NL}$ & ESNL & $\mathrm{L} 3<\mathrm{NL}$ & $\mathrm{L} B \mathrm{NL}$ & $\mathrm{B} 3 \mathrm{NNL}$ & L3CNL & L3SNLL. & L3NNL & LSPNL & LBSNL \\
\hline & $19 \times 11$ & $13 \times 11$ & $13<11$ & $13>11$ & $13 \ll 11$ & $t 3<t 1$ & $13>1$ & $13<11$ & $13<1.1$ & $13<11$ & $13 \times 11$ & $L 3<1.1$ \\
\hline
\end{tabular}

\section{Proposed MPU6050 Procedure Analysis}

The vibration data at $\mathrm{x}$-axis can identify the sizes of the leaks for all pressure except for $1.0 \mathrm{kgf} / \mathrm{cm}^{2}$. In contrast, the $\mathrm{z}$-axis can identify the water leakage at $1.0 \mathrm{kgf} / \mathrm{cm}^{2}$. On the other hand, the y-axis has a difficulty to differentiate the conditions of the water pipeline as well as the sizes of the leaks for all water pressure except for $0.6 \mathrm{kgf} / \mathrm{cm}^{2}$. Due to this fact, the procedure is designed only for $\mathrm{x}$ - and $\mathrm{z}$-axis, as depicted in Figure 7. Initially, the vibration data for $\mathrm{x}$ - and $\mathrm{z}$-axis of MPU6050 are collected and transmitted. Secondly, time domain analysis is used to identify the conditions of the water pipeline from the $\mathrm{x}$-axis data. Thirdly, if the conditions of the water pipeline can be detected, the sizes of the leaks can be differentiated whether it is a 1-mm or 3-mm leaks. If the size of the leak is 3-mm, then the pipeline must be repaired immediately. If the $\mathrm{x}$-axis is unsatisfactory to detect the conditions of the water pipeline, the z-axis will be analysed further using the time domain analysis, as can be seen in Figure 7.

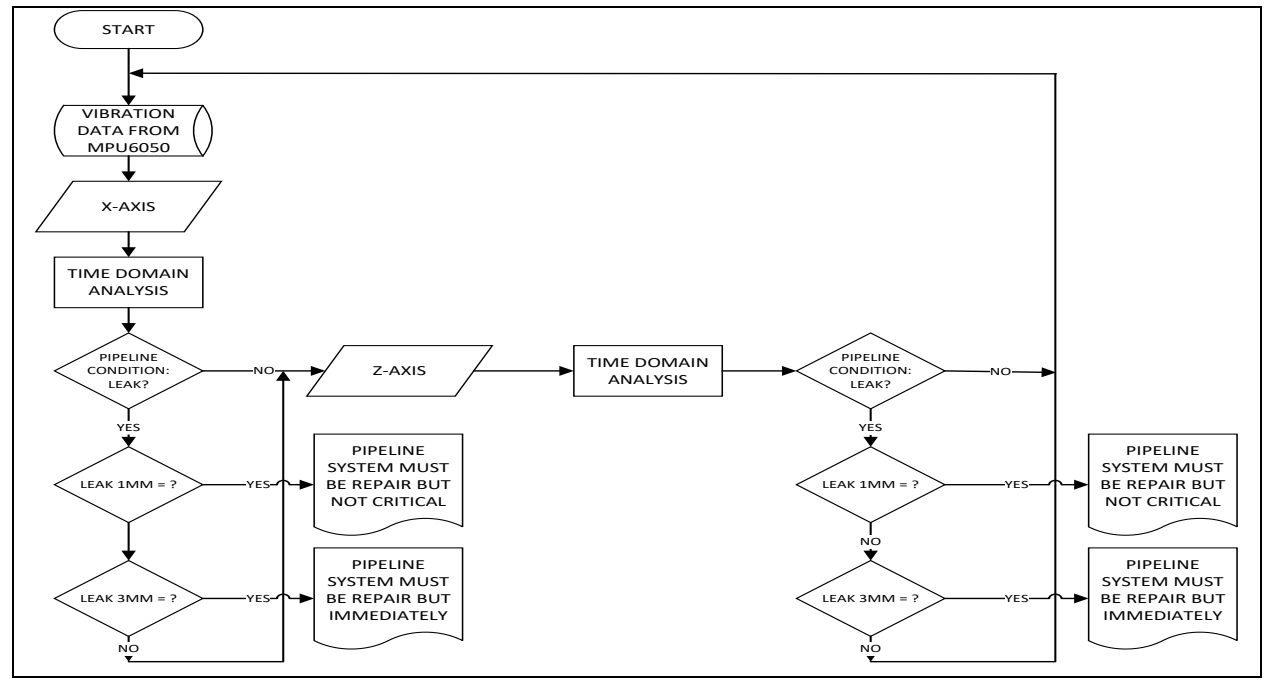

Figure 7. A Proposed Procedure of Water Pipeline Leakage Detection for MPU6050

\section{Conclusion}

This paper determined whether the vibration method using MPU6050 can identify the conditions of the water pipelines (both normal or abnormal) across $\mathrm{x}-, \mathrm{y}$ - and z-axis with varying water pressure from 0.6 to $1,2 \mathrm{kgf} / \mathrm{cm}^{2}$. The MPU6050 sensor can only recognise the conditions of the water pipeline and the sizes of the leaks across $\mathrm{x}$ - and z-axis for the water pressure varied between 0.6 and $1.2 \mathrm{kgf} / \mathrm{cm}^{2}$. Nevertheless, the vibration data from $\mathrm{y}$-axis is unreliable to detect the conditions of the water pipeline and sizes of leaks. Based on the new findings, this paper has also provided an MPU6050 procedure analysis using the $\mathrm{x}$ - and $\mathrm{z}$-axis for the water pipeline leakage detection. Future work should be undertaken to investigate the performance of other types of accelerometer sensors, such as ADL335 and MMA7361 in detecting the water pipeline leakage from the three axes. 


\section{References}

[1] Who Unicef, "Global Water Supply and Sanitation Assessment 2000 Report”, Water Supply, (2000), p. 87.

[2] R. McKenzie and C. Seago, "Assessment of real losses in potable water distribution systems: some recent developments", Water Sci. Technol. Water Supply, vol. 5, no. 1, (2005), pp. 33-40.

[3] "Non-Revenue Water (NRW) | Pure Technologies Ltd.", [Online]. Available: https://www.puretechltd.com/media/news-and-articles/nonrevenuewaternrw.

[4] N. A. M. Ir. Dr. Hasnul Mohammad Salleh, "Non-Revenue Water, Impact To The Service, Environment And Financial".

[5] F. Almeida, M. Brennan, P. Joseph, S. Whitfield, S. Dray and A. Paschoalini, "On the acoustic filtering of the pipe and sensor in a buried plastic water pipe and its effect on leak detection: an experimental investigation", Sensors (Basel), vol. 14, no. 3, (2014), pp. 5595-610.

[6] A. Sadeghioon, N. Metje, D. Chapman and C. Anthony, "SmartPipes: Smart Wireless Sensor Networks for Leak Detection in Water Pipelines", J. Sens. Actuator Networks, vol. 3, no. 1, (2014), pp. 64-78.

[7] H. Kakuta, K. Watanabe and Y. Kurihara, "development of vibration sensor with wide frequency range based on condenser microphone - estimate system for water flow rate in water pipes", World Academy of Science, Engineering \& Technology, 2012. [Online]. Available: http://waset.org/publications/8417/development-of-vibration-sensor-with-wide-frequency-range-basedon-condenser-microphone-estimation-system-for-flow-rate-in-water-pipes-. [Accessed: 29-Mar-2016].

[8] D. K. Masanobu Shinozuka, P.H. Chou, S. Kim and H. R. Kim dan Lu Fei, "Non-invasive AccelerationBased Methodology for Damage Detection and Assessment of Water Distribution System”, Smart Struct. Syst., vol. 6, no. 10, (2010), pp. 545-559.

[9] J. B. A. (KeTTHA), "Water Services Industry Performance Report 2011", 2012. [Online]. Available: www.kettha.gov.my.

[10] D. I. C. Covas, H. M. Ramos and A. B. de Almeida, "Closure to 'Standing Wave Difference Method for Leak Detection in Pipeline Systems' by Dídia I. C. Covas, Helena M. Ramos, and António Betâmio de Almeida", J. Hydraul. Eng., vol. 134, no. 7, (2008), pp. 1029-1033.

[11] J. Zhang, "Designing a cost-effective and reliable pipeline leak-detection system", Pipes Pipelines Int., vol. 42, no. 1, (1997), pp. 20-26.

[12] J. A. and L.-C. C. Liggett, "Inverse transient analysis in pipe networks", J. Hydraul. Eng., vol. 120, no. 8, (1994), pp. 934-955.

[13] B. Parry, R. Mactaggart and C. Toerper, "Compensated volume balance leak detection on a batched LPG pipeline", in Proceedings of the International Offshore Mechanics and Arctic Engineering Symposium, vol. 5, no. pt B, (1992), pp. 501-507.

[14] M. Stafford and N. Williams, "Pipeline leak detection study", (1996).

[15] J. Zhang, "Designing a cost-effective and reliable pipeline leak-detection system", Pipes Pipelines Int., vol. 42, no. 1, (1997), pp. 20-26.

[16] R. S. Whaley, J.V. Reet and R.E. Nicholas, "A tutorial on computer based leak detection methods", Texas, USA, (1992).

[17] J. Zhang, "Statistical pipeline leak detection for all operating conditions", Pipeline Gas J., vol. 229, no. 2, (2001), pp. 42-45.

[18] J. P. Wang, X. J. Lambert, M. F. Simpson, A. R. Liggett, J. A. \& V 1' tkovský, "Leak detection in pipelines using the damping of fluid transients", J. Hydraul. Eng., vol. 128, no. 7, (2002), pp. 697-711.

[19] L. Jönsson, "Interaction of a hydraulic transient with a leak in a pipe flow", 14th Australasian Fluid Mechanics Conference. Adelaide University, Adelaide, Australia, (2001).

[20] A. F. Colombo, P. Lee and B. W. Karney, "A selective literature review of transient-based leak detection methods", J. Hydro-environment Res., vol. 2, no. 4, (2009), pp. 212-227.

[21] R. A. Silva, "Pressure wave behaviour and leak detection in pipelines", Comput. \&amp; Chem. Eng., vol. 20, no. 0, pp. S491-S496, (1996).

[22] J. E. Hough, "Leak testing of pipelines uses pressure and acoustic velocity", Oil Gas J., vol. 86, no. 47, (1988).

[23] C. P. Liou, "Pipeline Leak Detection by Impulse Response Extraction”, J. Fluids Eng., vol. 120, no. 4, (1998), pp. 833-838.

[24] J. P. Vitkovsky, A.R. Simpson and M.F. Lambert, "Leak detection and calibration using transients and genetic algorithms”, J. Water Resour. Plan. Manag. 131, vol. 126, no. 4, (2000), pp. 262-265.

[25] X. J. Wang, "Leak detection in pipelines using the damping of fluid transients", J. Hydraul. Eng., vol. 128, no. 7, (2002), pp. 697-711.

[26] M. F. Ghazali and P. S. B. M. B. and P. W. J. Staszewski, "Leak Detection Using Instantaneous Frequency Analysis," University of Sheffield, Sheffield, (2012).

[27] I. Al-Shidhani, S. B. M. Beck and W. J. Staszewski, "Leak monitoring in pipeline networks using wavelet analysis", in Key Engineering Materials, vol. 245-246, (2003), pp. 51-58.

[28] M. J. Brennan, Y. Gao and P. F. Joseph, "On the relationship between time and frequency domain methods in time delay estimation for leak detection in water distribution pipes", J. Sound Vib., vol. 304, no. 1-2, (2007), pp. 213-223. 
[29] M. Ferrante and B. Brunone, "Pipe system diagnosis and leak detection by unsteady-state tests. 2. Wavelet analysis", Adv. Water Resour., vol. 26, no. 1, (2003), pp. 107-116.

[30] L. Jönsson and Dept. of Water Resources Engineering, "Hydraulic transients as a monitoring device", University of Lund, Lund, Sweden, (1995).

[31] A. K. Soares, D. I. C. Covas and L. F. R. Reis, "Inverse transient analysis for leak detection in a PVC pipe network", in Proceedings of the Combined International Conference of Computing and Control for the Water Industry, CCWI2007 and Sustainable Urban Water Management, SUWM2007, (2007), pp. 337-344.

[32] E. Farmer, R. Kohlrust, G. Myers and G. Verduzco, "Leak-detection tool undergoes field tests", Oil Gas J., vol. 86, no. 51, pp. 48-53, (1988).

[33] O. and G. Hunaidi P., "Ground-penetrating radar for detection of leaks in buried plastic water distribution pipes", Proc. 7th Int. Conf. Gr. Penetrating Radar, (1998).

[34] O. Hunaidi, W. Chu, A. Wang and W. Guan, "Detecting leaks in plastic pipes", J. / Am. Water Work. Assoc., vol. 92, no. 2, (2000), pp. 82-94.

[35] O. Hunaidi, "Detecting Leaks in Water-Distribution Pipes", Inst. Res. Constr., no. October, (2000), pp. $1-6$.

[36] N. D. and J. F. Maninder Pal, "Detecting and Locating Leaks in Water Distribution Polyethylene Pipes," Proc. World Congr. Eng., vol. 2, (2010).

[37] R. A. D. and N. A. A. @ S. MIM Ismail, “A Comparative Study of Wireless Accelerometer Sensors for Water Pipeline Leakage", in 2015 IEEE International Symposium on Robotics and Intelligent Sensors (IEEE - IRIS 2015), (2015).

[38] M. Ismail, R. A. Dziyauddin and N. A. A. Salleh, "Performance evaluation of wireless accelerometer sensor for water pipeline leakage", 2015 IEEE International Symposium on Robotics and Intelligent Sensors (IRIS), (2015), pp. 120-125.

[39] M. I. M. Ismail, R. A. Dziyauddin and N. A. A. Samad, "Water pipeline monitoring system using vibration sensor", in 2014 IEEE Conference on Wireless Sensors (ICWiSE), (2014), pp. 79-84.

[40] M. Shinozuka, P. H. Chou, S. Kim, H. R. Kim, E. Yoon, H. Mustafa, D. Karmakar and S. Pul, "Nondestructive monitoring of a pipe network using a MEMS-based wireless network", Proc. SPIE Nondestruct. Charact. Compos. Mater. Aerosp. Eng. Civ. Infrastructure, Homel. Secur., vol. 7649, (2010), p. 76490P.

[41] A. A. C. Nwalozie and C. Gerald, "Design and implementation of pipeline monitoring system using acceleration-based wireless sensor network", (IJES), The International Journal Of Engineering And Science, 2014. [Online]. Available: http://www.theijes.com/papers/v3-i9/Version-3/G0393049058.pdf. [Accessed: 29-Mar-2016].

[42] A. Sadeghioon, N. Metje, D. Chapman and C. Anthony, "SmartPipes: Smart Wireless Sensor Networks for Leak Detection in Water Pipelines", J. Sens. Actuator Networks, vol. 3, no. 1, (2014), pp. 64-78.

[43] M. K. Chamran and S. Shafie, "A Non-Invasive Air-Coupled V-Type Ultrasonic Leak Detection System", Journal of Purity, Utility Reaction and Environment, vol. 4, no. 3, (2015).

[44] M. K. Chamran and S. Shafie, "Non-invasive application for domestic pipeline monitoring and corrosion detection", in 2013 IEEE International Conference on Smart Instrumentation, Measurement and Applications (ICSIMA), (2013), pp. 1-6.

[45] Z. Li, "Leak Detection by Multi-sensor Fusion Method", (2012).

[46] F. Yang, "Water Leak Detection and Localization Using Multi-Sensor Data Fusion", (2012).

[47] J. Hester, T. King, A. Propst, K. Piratla and J. Sorber, "Enabling sustainable sensing in adverse environments", in 2013 IEEE International Conference on Sensing, Communications and Networking (SECON), (2013), pp. 249-251.

[48] A. Martini, M. Troncossi and A. Rivola, "Automatic Leak Detection in Buried Plastic Pipes of Water Supply Networks by Means of Vibration Measurements", Shock Vib., vol. 2015, (2015), pp. 1-13.

[49] N. G.C, A. A.C.O, O. A.C and A. E, "Development of an acceleration-based wireless sensor node platform", International Journal of Advanced Research in Computer and Communication Engineering Vol. 3, Issue 9, September 2014, 2014. [Online]. Available: http://www.ijarcce.com/upload/2014/september/IJARCCE1H a gechug Development of an Acceleration-based Wireless Sensor Node Platform.pdf. [Accessed: 04-Apr-2016].

[50] M. T. and A. R. Alberto Martini, "Vibration monitoring as a tool leak detection in water distribution networks", in Surveillance 7, At Chartres (France), October 2013, (2013), pp. 1-9.

[51] L. Wang, A. D. Hope and H. Sadek, "Vibration-based condition monitoring of pumps in the waste water industry", Insight, vol. 42, no. 8, (2000), pp. 500-503.

[52] S. R. Hayashi, C. E. Thomas, D. G. Wildes and G. Tlusty, "Tool Break Detection by Monitoring Ultrasonic Vibrations", CIRP Ann. - Manuf. Technol., vol. 37, no. 1, (1988), pp. 61-64.

[53] A. Martini, M. Troncossi, A. Rivola and D. Nascetti, "Advances in Condition Monitoring of Machinery in Non-Stationary Operations", Berlin, Heidelberg: Springer Berlin Heidelberg, vol. 5, (2014).

[54] M. J. Brennan Y. Gao and P.F. Joseph, "On the relationship between time and frequency domain methods in time delay estimation for leak detection in water distribution pipes", J. Sound Vib., vol. 304, no. 1-2, (2007), pp. 213-223.

[55] "Failure Modes and Mechanisms in Gray Cast Iron Pipes", Underground Infrastructure Research 2001, 
Waterloo,

Ontario,.

[Online].

Available: http://citeseerx.ist.psu.edu/viewdoc/download?doi=10.1.1.4.2771\&rep=rep1\&type=pdf. [Accessed: 16Mar-2016].

[56] J. Becker, "National report - USA", Water Supply, vol. 14, no. 3-4, (1996), pp. 249-250.

[57] J. A. and L.-C. C. Liggett, "Inverse transient analysis in pipe networks for leakage detection, quantification and roughness calibration", J. Hydraul. Eng., vol. 120, no. 8, (1994), pp. 934-955.

[58] J. E. Hough, "Leak testing of pipeline uses pressure and acoustic velocity", Oil Gas J., vol. 86, no. 47, (1988), p. 6.

[59] N. C. Gerald and A. Aco, "Design and Implementation of Pipeline Monitoring System Using Acceleration-Based Wireless Sensor Network" Int. J. Eng. Sci., pp. 2319-1813.

\section{Authors}

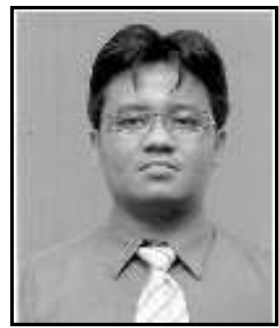

Mohd Ismifaizul bin Mohd Ismail, he is a Doctor Philosophy student at Razak School of Science and Advanced Technology, Universiti Teknologi Malaysia in Kuala Lumpur Campus. He graduates from Universiti Teknologi Malaysia (UTM) with Master Philosophy on 2017. He has experienced in teaching, R\&D and development electronic product for education and industry. On the other hand, he has been award as Excellent Scientist on 2004 from Ministry of Education (MOHE). He has been awarded bronze medal at Salon International Des Inventions GENEVE 2005 and silver medal Invention, innovation and design UiTM 2004. His research interests include smart applications, wireless sensor tracking and positioning (outdoor), Internet of Think (IoT) application, control and monitoring system.

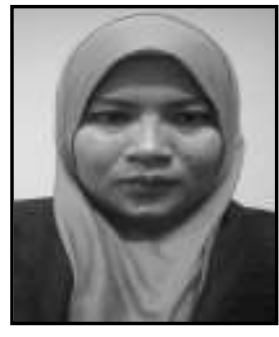

Rudzidatul Akmam Binti Dziyauddin, she is a Senior Lecturer at Razak School of Science and Advanced Technology, Universiti Teknologi Malaysia in Kuala Lumpur Campus. She received B.Eng in Electrical \& Electronic from USM, MSc in IT \& Science Qualitative from UiTM and PhD from University of Bristol, UK. In 2000 , she had worked at telecommunication industry called Celcom as an Engineer for almost four years. In 2012, she had an internship at Toshiba Research Europe Limited (TREL), UK for a year, and produced two patents related to intercell interference mitigation techniques. Her research interests include smart applications, scheduling, resource allocation, power control, energy efficiency and cross layer design MAC.

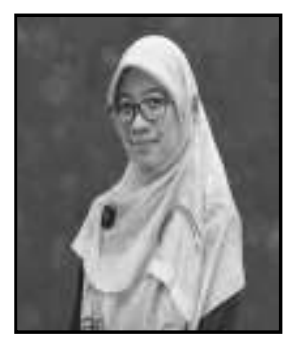

Noor Azurati binti Ahmad, she is a senior lecturer at Advanced Informatics School (UTM AIS), Universiti Teknologi Malaysia Kuala Lumpur. She obtained her B.Eng. in Computer Engineering in 2001 and Master of Electrical Engineering in 2006 from Universiti Teknologi Malaysia. She graduated with a $\mathrm{PhD}$ in Embedded Systems from University of Leicester in 2013. She is a Certified Tester Foundation Level (CTFL) under Malaysian Software Testing Board (MSTB) and Certified Professional for Requirements Engineering (CPRE) under International Requirements Engineering Board (IREB). Her current research explorations are on Smart City, Smart Campus, Indoor Positioning System and Green ICT. 


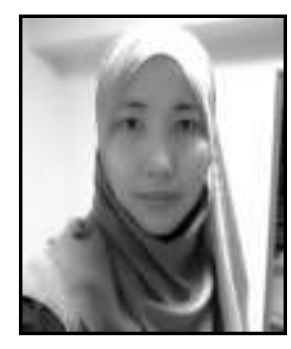

Norulhusna Ahmad, she graduated from Universiti Teknologi Malaysia (UTM) in 2001 with Bsc in Electrical Engineering. She joined UTM as staff and later pursuing her study at same university. She received her master degree of Electrical Engineering (Telecommunication) and $\mathrm{PhD}$ in Electrical Engineering in 2003 and 2014, respectively. Currently, she is a lecturer at Razak School of Science and Advanced Technology, UTM KL. Her expertise is on the area of digital signal processing and wireless communication. Her research interests are future communication such as $5 \mathrm{G}$ and cognitive radio focusing on error correcting codes, turbo equalization, OFDM, resource allocation, network coding and cooperative communication. 
International Journal of Advanced Science and Technology

Vol.112 (2018) 